\title{
PAPER
}

\section{The relative health related quality of life of veterans with Parkinson's disease}

\author{
H Gage, A Hendricks, S Zhang, L Kazis
}

J Neurol Neurosurg Psychiatry 2003;74:163-169

\begin{abstract}
Objectives: To use databases of the US Veterans Health Administration (VHA) to describe the impact of Parkinson's disease on health related quality of life (HRQoL) of veterans; to compare the HRQoL of veterans with Parkinson's disease with that of veterans reporting eight other neurological or chronic conditions; and to estimate the unique effect of Parkinson's disease on HRQoL.

Methods: Respondents to the VHA 1999 large national health survey of veteran enrollees with a diagnosis of Parkinson's disease in VHA treatment files for the fiscal years 1997-1999 were identified by merging databases. The survey incorporated the Veterans SF-36, a well validated generic measure of HRQoL and functional status. This was used to compare patient groups. Mean physical (PCS) and mental (MCS) component summary scores were calculated for Parkinson's disease and eight other diseases by multivariable regressions that adjusted for age, sex, race, education, and 15 mental and physical co-morbid conditions that were self reported in the survey. Results: Of 887775 survey respondents, 14530 (1.64\%) had a Parkinson's disease diagnosis. Controlling for sociodemographic factors and co-morbidities, veterans with Parkinson's disease had PCS and MCS below veterans with angina/coronary heart disease, arthritis, chronic low back pain, congestive heart failure, diabetes, and stroke. Veterans with spinal cord injury reported slightly lower PCS than veterans with Parkinson's disease $(32.38 \vee 32.72 ; 0.03$ of 1 SD). Veterans with depression reported markedly lower MCS than veterans with Parkinson's disease (35.94 v $41.48 ; 0.55$ of 1 SD). The unique effect of having Parkinson's disease on HRQoL was to lower PCS and MCS by 4.10 and 3.42 points $(0.41$ and 0.34 of $1 \mathrm{SD})$, respectively.

Conclusions: The analysis quantifies the negative impact of Parkinson's disease on HRQoL, after controlling for sociodemographic factors and co-morbidities. Compared with eight other chronic conditions, Parkinson's disease imposes a relatively heavy burden on US veterans in the VHA health care system.
\end{abstract}

See end of article for authors' affiliations

Ms Heather Gage,

Department of Economics,

University of Surrey,

Guildford GU2 7XH

h.gage@surrey.ac.uk

Received 5 March 2002

In revised form

3 September 2002

Accepted

1 November 2002
$\mathrm{P}$ atients' perceptions about how their illness affects them in their daily lives can differ from those of their practitioners ${ }^{1-3}$ and informal caregivers. ${ }^{4}$ It is particularly important that clinicians understand how patients experience chronic and often incurable conditions such as Parkinson's disease, where the goals of treatment are to optimise their quality of life. ${ }^{5}$ Parkinson's disease gives rise to a range of physically disabling and socially distressing symptoms. ${ }^{67}$ Empirical information about the impact of disease can be gathered from patients by measures of health related quality of life (HRQoL). ${ }^{8}$ In combination with clinical indicators, HRQoL data contribute to the appreciation of the overall impact of disease on patients. ${ }^{9}$

Formal study of HRQoL is only about 25 years old, and has grown substantially over the last decade. ${ }^{8}$ Although methodological and conceptual challenges remain, ${ }^{510}$ HRQoL as an outcome has become an important standard for use in health care interventions. It can also be used as a basis for assessing the health status of populations, and to judge the burden of disease by comparing clinical groups with the general population. At an individual level, HRQoL has been shown to be a sound predictor of mortality and morbidity, ${ }^{11}$ although available measures are not always appropriate for use in routine clinical practice. ${ }^{12}$

The most commonly used HRQoL instruments are measures which characterise patients using multidimensions or scales. ${ }^{13}$ A distinction is drawn between generic and disease specific measures of HRQoL. ${ }^{3}$ Although there is debate about the appropriate dimensions to include, ${ }^{14}$ generic assessments often cover measures of physical functioning, independence of living, emotional/mental wellbeing, and the effects of disease on work and social activity. They allow broad population level analyses and comparisons between patient groups, but they do not focus on the special features of particular conditions that cause concern to the sufferers.

The Veterans Administration health care system (VHA) is one of the largest integrated systems nationally in the USA, with around 145 medical centres in the 50 states. This system, which is federally funded, provides comprehensive care to most veteran patients with service connected disabilities or who qualify economically. Veterans who use the VHA tend to be more disabled, economically disadvantaged, and have more complex medical and mental health problems than the general US population or veterans who do not use the VHA system. ${ }^{15}$ Because the VHA recognises the importance of monitoring the health outcomes of veterans using measures of functional status, HRQoL assessments are increasing on a national basis. One of the most widely used generic measures in the VHA is the Veterans SF-36 (V/SF-36), adapted and modified from the medical outcomes study (MOS) version of the SF-36. ${ }^{16-19}$

In this study we used the V/SF-36 to evaluate the impact of Parkinson's disease on HRQoL in a large VHA national sample $(n=14530)$ of veterans diagnosed with Parkinson's disease.

Abbreviations: $H R Q \circ L$, health related quality of life; MCS, mental component summary score of SF-36; MOS, medical outcomes study; PCS, physical component summary score of SF-36; RE, role, emotional; RP, role, physical; SF-36, short form 36 item health status questionnaire; VHA, Veterans Administration health care system; V/SF-36, Veterans short form 36 item health status questionnaire 
Table 1 SF-36 items, scales, and component summaries*

\begin{tabular}{|c|c|c|c|}
\hline Scales (items) & $\begin{array}{l}\text { Component summary } \\
\text { measure }\end{array}$ & Scales (items) & $\begin{array}{l}\text { Component summary } \\
\text { measure }\end{array}$ \\
\hline $\begin{array}{l}\text { Physical functioning (PF) (10 } \\
\text { items: ability to undertake } \\
\text { activities, carry, walk, climb } \\
\text { stairs, bend, kneel, bathe, } \\
\text { dress) }\end{array}$ & $\begin{array}{l}\text { Physical component } \\
\text { summary (PCS) }\end{array}$ & $\begin{array}{l}\text { Vitality (VT) (four items: } \\
\text { energy, fatigue) }\end{array}$ & $\begin{array}{l}\text { Mental component } \\
\text { summary (MCS) }\end{array}$ \\
\hline $\begin{array}{l}\text { Role physical (RP) (four items: } \\
\text { physical limitations to activity) }\end{array}$ & & $\begin{array}{l}\text { Social functioning (SF) (two } \\
\text { items: engagement in social } \\
\text { activity) }\end{array}$ & \\
\hline $\begin{array}{l}\text { Bodily pain (BP) (two items: } \\
\text { magnitude and interference of } \\
\text { pain) }\end{array}$ & & $\begin{array}{l}\text { Role emotional (RE) (three } \\
\text { items: emotional limitations } \\
\text { to activities) }\end{array}$ & \\
\hline $\begin{array}{l}\text { General health }(\mathrm{GH} \text { ) (four } \\
\text { items: perceptions of health } \\
\text { status) }\end{array}$ & & $\begin{array}{l}\text { Mental health (MH) (five } \\
\text { items: nervous, peaceful, } \\
\text { sad, happy) }\end{array}$ & \\
\hline
\end{tabular}

The statistical power from this large number of subjects has advantages over previous studies that collected data from fewer than 250 respondents. ${ }^{20-22}$ The self reported HRQoL of veterans with Parkinson's disease is compared with that of the veterans without Parkinson's disease, and also with that of veterans reporting eight other neurological or chronic diseases. To our knowledge, there have been no previous studies that have examined the relative illness burden of Parkinson's disease. Many people with chronic disease suffer from multiple conditions, and the use of a generic instrument enables the health status of these people to be monitored ${ }^{23}$ We used multivariable statistical techniques to control for sociodemographic differences and co-morbid conditions so that the independent impact of particular diseases can be calculated and the unique effect of Parkinson's disease on HRQoL can be estimated.

\section{METHODS \\ Data}

The study population is US veterans enrolled in the VHA. All veterans have the option of enrolling in VHA, and eligibility is defined by seven priority categories:

- groups 1,2, and 3: veterans with service connected disability of $\geqslant 50 \%, 30-40 \%$, and $10-20 \%$ respectively, and former prisoners of war;

- group 4: veterans who are catastrophically disabled, housebound, needing aid and attendance;

- group 5: veterans with income and net worth below established thresholds;

- group 6: veterans of World War I, "agent orange," and "Gulf War syndrome";

- group 7: veterans who do not qualify under priority areas 1-6 but may make co-payments for VHA services according to fixed schedules.

Overall, $72.6 \%$ of VHA enrollees have alternative health care coverage besides VHA: $52.7 \%$ have Medicare (federal coverage for the aged or disabled), 19.1\% have only private insurance, and $1 \%$ have only Medicaid (public coverage for the indigent). In $1999,38.2 \%$ of enrollees exclusively used VHA for health care. $^{24}$

Inspection of VHA administrative data for the fiscal years 1997 to 1999 showed there were 55637 veterans with a diagnosis of Parkinson's disease (ICD-9-CM codes 332.0: Parkinson's disease; 333.0: other degenerative diseases of the basal ganglia, including Parkinsonian syndromes; 333.1: essential and other specified forms of tremor). This file was merged with data from the 1999 VHA large national health survey of veteran enrollees, ${ }^{19}$ which had randomly sampled 1.4 million VHA enrollees, stratified for priority status, from a total VHA population of approximately 3.5 million, between July 1999 and January 2000. In this way we were able to identify survey respondents with a recent diagnosis of Parkinson's disease.

The core section of the 1999 VHA large national health survey, which was completed by all respondents, collected data by means of a structured questionnaire on sociodemographic factors and health status. To measure the prevalence of chronic diseases, veterans were asked whether or not a doctor had ever told them they had each of 15 conditions (angina/coronary heart disease, arthritis, benign prostatic hypertrophy, cancer, chronic low back pain, chronic lung disease, congestive heart failure, depression, diabetes, hypertension, myocardial infarction, post-traumatic stress disorder, schizophrenia, spinal cord injury, stroke). Health status was measured using V/SF-36.

As shown in table 1, SF-36 comprises 36 items, which are combined into eight scales and summarised into the physical (PCS) and mental summary (MCS) scores. Items from each SF-36 scale were summed and raw scores were rescaled with a standard range 0 (worst) to 100 (best). The eight scales were combined into the two component summaries (PCS and MCS), using weights derived from a national probability sample. Each summary was then standardised with a mean of 50 and a standard deviation of 10. This process allows comparison across populations. Summaries have a consistent power advantage over scales, given their increased precision. ${ }^{25}$

The reliability and validity of the modified SF-36 is well established in VHA populations and, as in the MOS SF-36 version, normalised to a US population. ${ }^{25-32}$ The V/SF-36 uses five point ordinal choices (no, none of the time, to yes, all of the time) in the physical role limitations (RP) and emotional role limitations (RE) scales, instead of dichotomised two point choices (yes/no), and adds about 5\% to the precision of the PCS and MCS scores compared with the MOS SF-36..$^{18} 1926$

In addition to the core questionnaire, the VHA large national health survey included five modules-each allocated to a random $20 \%$ of sample members-on smoking and alcohol, diet and physical activity, satisfaction with care and the doctor-patient relationship, social support, and health care insurance and utilisation. Two sets of weights were applied to responses: first, to make the samples representative of the complete veteran enrollee population; and second, to correct for the extent that responses were not randomly distributed across all demographic groups.

\section{Analysis}

First, the socioeconomic, demographic, health, and service utilisation characteristics of survey respondents with Parkinson's 
Table 2 Comparison of characteristics of veterans with and without a diagnosis of Parkinson's disease

\begin{tabular}{|c|c|c|}
\hline Characteristic & $\begin{array}{l}\text { Per cent of } \\
\text { veterans with } \\
\text { PD }\end{array}$ & $\begin{array}{l}\text { Per cent of } \\
\text { veterans without } \\
\text { PD }\end{array}$ \\
\hline (1) Age $\geqslant 65$ years & 76.26 & 44.04 \\
\hline (2) Male & 97.56 & 95.18 \\
\hline \multicolumn{3}{|l|}{ (3) Race } \\
\hline White & 83.42 & 72.74 \\
\hline Black & 7.95 & 15.52 \\
\hline \multicolumn{3}{|l|}{ (4) Employment } \\
\hline Employed & 10.08 & 35.17 \\
\hline Retired & 65.86 & 43.10 \\
\hline Unable to work & 22.44 & 16.55 \\
\hline $\begin{array}{l}\text { (5) Education } \leqslant 12 \text { th grade } \\
\text { (6) VHA priority }\end{array}$ & 64.47 & 53.60 \\
\hline 4 (catastrophic disability) & 8.71 & 2.64 \\
\hline 7 (no disability: co-pay) & 9.31 & 12.77 \\
\hline \multicolumn{3}{|c|}{ (7) Source of health care in past three years } \\
\hline VHA only & 42.23 & 34.94 \\
\hline No VHA use & 3.15 & 14.25 \\
\hline Dual use & 53.22 & 45.71 \\
\hline \multicolumn{3}{|l|}{ (8) Planned future use of VHA } \\
\hline Primary source & 78.16 & 66.22 \\
\hline Back up & 15.11 & 26.69 \\
\hline Prescription only & 5.57 & 4.12 \\
\hline None & 1.16 & 2.98 \\
\hline (9) Takes no regular exercise & 57.77 & 35.89 \\
\hline $\begin{array}{l}\text { (10) Physical health worse than } \\
\text { one year ago }\end{array}$ & 56.98 & 39.36 \\
\hline $\begin{array}{l}\text { (11) Emotional health worse than } \\
\text { one year ago }\end{array}$ & 37.80 & 26.89 \\
\hline (12) Enrolled in Medicare & 78.80 & 52.30 \\
\hline $\begin{array}{l}\text { With private insurance (no } \\
\text { Medicare) }\end{array}$ & 4.44 & 19.13 \\
\hline $\begin{array}{l}\text { Rely } 100 \% \text { on VHA outpatient } \\
\text { care }\end{array}$ & 45.07 & 33.16 \\
\hline
\end{tabular}

Differences are significant for all characteristics $(p<0.001)$. Data were calculated from the 1999 VHA large national health survey of veteran enrollees.

Items $1-11$ were drawn from the core questionnaire $(n=887775$, of which 14530 (1.64\%) had a diagnosis of Parkinson's disease). Item 12 was taken from the insurance and utilisation module $(n=$ 152253 , of which 2335 (1.53\%) had Parkinson's disease). PD, Parkinson's disease.

disease were compared with those of respondents without a diagnosis of Parkinson's disease using $\chi^{2}$ tests of association.

Second, differences in HRQoL between groups of survey respondents were assessed. We used SUDAAN, a software package specifically designed for statistical testing of complex sample datasets. ${ }^{33}$ Two multivariable least squares regression models (for PCS and MCS) calculated the mean V/SF-36 summary scores for veterans with Parkinson's disease and veterans with eight other chronic diseases (angina/coronary heart disease, arthritis, chronic low back pain, congestive heart failure, depression, diabetes, spinal cord injury, stroke). These eight neurological and chronic conditions were selected for comparison with Parkinson's disease from the 15 self reported by survey respondents, because of their established adverse effects on HRQoL. ${ }^{19}$

Twenty variables were entered into the regression models: four sociodemographic characteristics (age, sex, race, education) that are known to influence HRQoL, ${ }^{28}$ a dichotomised variable showing whether or not respondents had a diagnosis of Parkinson's disease in VHA treatment files in the fiscal years 1997 to 1999, and 15 dichotomised variables for whether or not respondents had self reported each of the chronic conditions included in the survey. The age and race variables were each split into three categories for the purposes of the regression analysis (18-50, 51-65, > 65 years; white, black, other races). Education was divided into two categories, defined by whether or not the respondent had received more than 12 years of education.
The regression coefficients for each disease indicate an effect size: the difference in PCS (or MCS) between veterans with the disease and veterans without it, after controlling for the effect of four sociodemographic features and $15 \mathrm{co}-$ morbidities. The effect size indicates the independent or unique impact of each disease on HRQoL. Results are presented here for Parkinson's disease and the eight selected comparison conditions.

\section{RESULTS}

\section{Descriptive analysis of sample}

Of 887775 respondents to the 1999 VHA large national health survey (overall response rate 63.1\%), 14530 (1.6\%) had a diagnosis of Parkinson's disease in VHA treatment files for fiscal years 1997 to 1999.

The characteristics of survey respondents with a diagnosis of Parkinson's disease are compared with those of respondents without Parkinson's disease in table 2. As might be expected with denominators of this magnitude, differences between groups were significant for all characteristics $(p<0.001)$, but small differences may not be important. Compared with other veterans, those with Parkinson's disease were more likely to be 65 years of age or older, white, retired, have had 12 or fewer years of education, be catastrophically disabled, be enrolled in Medicare, rely exclusively on the VHA for health care services, and report recent deteriorations in physical and mental health.

Veterans with Parkinson's disease reported, on average, 4.0 co-morbid conditions, compared with 3.2 among veterans without Parkinson's disease. All recorded conditions were significantly more prevalent among veterans with Parkinson's disease $(p<0.001)$. Table 3 shows that the largest differences between subjects with and without a diagnosis of Parkinson's disease were recorded for stroke, arthritis, benign prostatic hypertrophy, depression, and heart problems. Unadjusted mean PCS and MCS scores for veterans with Parkinson's disease were, respectively, 6.9 and 5.7 points ( 0.69 and 0.57 of l SD) below those of veterans without Parkinson's disease.

Table 3 Self reported co-morbidities and unadjusted component summary scores of veterans with and without Parkinson's disease

\begin{tabular}{lcc}
\hline Self reported co-morbidity & $\begin{array}{l}\text { Per cent of } \\
\text { veterans with }\end{array}$ & $\begin{array}{l}\text { Per cent of } \\
\text { veterans } \\
\text { without PD }\end{array}$ \\
\hline Angina/coronary heart disease & 25.05 & 18.55 \\
Arthritis & 58.01 & 50.10 \\
Benign prostatic hypertrophy & 35.64 & 23.15 \\
Cancer & 14.66 & 10.83 \\
Chronic low back pain & 42.87 & 39.86 \\
Chronic lung disease & 21.83 & 19.26 \\
Congestive heart failure & 20.49 & 13.29 \\
Depression & 42.80 & 29.40 \\
Diabetes & 21.33 & 18.74 \\
Hypertension & 52.96 & 49.57 \\
Myocardial infarction & 20.01 & 15.36 \\
Post-traumatic stress disorder & 17.66 & 14.02 \\
Schizophrenia & 6.15 & 4.12 \\
Spinal cord injury & 4.60 & 3.62 \\
Stroke & 19.39 & 8.65 \\
Mean number of chronic conditions & 4.03 & 3.19 \\
Unadjusted physical component & 30.09 & 37.01 \\
summary (PCS) & & \\
Unadjusted mental component & 39.42 & 45.16 \\
summary (MCS) & & \\
\hline
\end{tabular}

Difference are all significant $(p<0.001)$.

Data were calculated from 1999 VHA large national health survey of veteran enrollees, core module, $n=887775$, of which 14530

(1.64\%) had a diagnosis of Parkinson's disease.

PD, Parkinson's disease. 
Table 4 The relative health related quality of life of veterans with Parkinson's disease and self reporting eight other chronic diseases, adjusted for age, sex, race, education, and 15 co-morbid conditions

\begin{tabular}{|c|c|c|c|c|c|c|c|c|}
\hline \multirow[b]{2}{*}{$\begin{array}{l}\text { Chronic condition } \\
\text { (1) }\end{array}$} & \multirow[b]{2}{*}{$\begin{array}{l}\text { Per cent of core } \\
\text { population } \\
\text { (weighted n) } \\
\text { (2) }\end{array}$} & \multirow{2}{*}{$\begin{array}{l}\text { Mean (SD) } \\
\text { number of self } \\
\text { reported chronic } \\
\text { conditions } \\
\text { (3) }\end{array}$} & \multicolumn{2}{|c|}{$\begin{array}{l}\text { Mean (SE) physical } \\
\text { component summary score }\end{array}$} & \multirow{2}{*}{$\begin{array}{l}\text { Mean effect of } \\
\text { condition on } \\
\text { PCS in points } \\
\text { (SE) } \\
\text { (6) }\end{array}$} & \multicolumn{2}{|c|}{$\begin{array}{l}\text { Mean (SE) mental } \\
\text { component summary score }\end{array}$} & \multirow{2}{*}{$\begin{array}{l}\text { Mean effect of } \\
\text { condition on } \\
\text { MCS in points } † \\
\text { (SE) } \\
\text { (9) }\end{array}$} \\
\hline & & & $\begin{array}{l}\text { With } \\
\text { condition } \\
\text { (4) }\end{array}$ & $\begin{array}{l}\text { Without } \\
\text { condition } \\
\text { (5) }\end{array}$ & & $\begin{array}{l}\text { With } \\
\text { condition } \\
\text { (7) }\end{array}$ & $\begin{array}{l}\text { Without } \\
\text { condition } \\
\text { (8) }\end{array}$ & \\
\hline Spinal cord injury & $\begin{array}{l}3.6 \% \\
(116189)\end{array}$ & $\begin{array}{l}5.10 \\
(0.006)\end{array}$ & $\begin{array}{l}32.38 \\
(0.069)\end{array}$ & $\begin{array}{l}36.93 \\
(0.013)\end{array}$ & $\begin{array}{l}-4.55 \\
(0.070)\end{array}$ & $\begin{array}{l}44.00 \\
(0.075)\end{array}$ & $\begin{array}{l}44.89 \\
(0.014)\end{array}$ & $\begin{array}{l}-0.89 \\
(0.077)\end{array}$ \\
\hline Depression & $\begin{array}{l}29.6 \% \\
(946693)\end{array}$ & $\begin{array}{l}4.96 \\
(0.005)\end{array}$ & $\begin{array}{l}35.88 \\
(0.026)\end{array}$ & $\begin{array}{l}37.17 \\
(0.017)\end{array}$ & $\begin{array}{l}-1.29 \\
(0.033)\end{array}$ & $\begin{array}{l}35.94 \\
(0.030)\end{array}$ & $\begin{array}{l}48.89 \\
(0.018)\end{array}$ & $\begin{array}{l}-12.95 \\
(0.038)\end{array}$ \\
\hline Parkinson's disease & $\begin{array}{l}1.2 \% \\
(39405)\end{array}$ & $\begin{array}{l}4.01 \\
(0.024)\end{array}$ & $\begin{array}{l}32.72 \\
(0.096)\end{array}$ & $\begin{array}{l}36.82 \\
(0.013)\end{array}$ & $\begin{array}{l}-4.10 \\
(0.096)\end{array}$ & $\begin{array}{l}41.48 \\
(0.106)\end{array}$ & $\begin{array}{l}44.91 \\
(0.014)\end{array}$ & $\begin{array}{l}-3.42 \\
(0.107)\end{array}$ \\
\hline $\begin{array}{l}\text { Congestive heart } \\
\text { failure }\end{array}$ & $\begin{array}{l}13.4 \% \\
(428538)\end{array}$ & $\begin{array}{l}6.39 \\
(0.007)\end{array}$ & $\begin{array}{l}33.68 \\
(0.035)\end{array}$ & $\begin{array}{l}37.25 \\
(0.014)\end{array}$ & $\begin{array}{l}-3.57 \\
(0.038)\end{array}$ & $\begin{array}{l}42.78 \\
(0.040)\end{array}$ & $\begin{array}{l}45.19 \\
(0.015)\end{array}$ & $\begin{array}{l}-2.41 \\
(0.044)\end{array}$ \\
\hline Stroke & $\begin{array}{l}8.8 \% \\
(281760)\end{array}$ & $\begin{array}{l}5.82 \\
(0.009)\end{array}$ & $\begin{array}{l}33.69 \\
(0.041)\end{array}$ & $\begin{array}{l}37.06 \\
(0.013)\end{array}$ & $\begin{array}{l}-3.37 \\
(0.06)\end{array}$ & $\begin{array}{l}43.13 \\
(0.046)\end{array}$ & $\begin{array}{l}45.03 \\
(0.014)\end{array}$ & $\begin{array}{l}-1.89 \\
(0.048)\end{array}$ \\
\hline Chronic low back pain & $\begin{array}{l}39.9 \% \\
(1276539)\end{array}$ & $\begin{array}{l}4.60 \\
(0.004)\end{array}$ & $\begin{array}{l}33.76 \\
(0.021)\end{array}$ & $\begin{array}{l}38.89 \\
(0.018)\end{array}$ & $\begin{array}{l}-5.14 \\
(0.028)\end{array}$ & $\begin{array}{l}43.67 \\
(0.023)\end{array}$ & $\begin{array}{l}45.70 \\
(0.019)\end{array}$ & $\begin{array}{l}-2.04 \\
(0.031)\end{array}$ \\
\hline Arthritis & $\begin{array}{l}50.2 \% \\
(1606481)\end{array}$ & $\begin{array}{l}4.46 \\
(0.003)\end{array}$ & $\begin{array}{l}34.15 \\
(0.018)\end{array}$ & $\begin{array}{l}39.59 \\
(0.020)\end{array}$ & $\begin{array}{l}-5.44 \\
(0.028)\end{array}$ & $\begin{array}{l}44.57 \\
(0.020)\end{array}$ & $\begin{array}{l}45.16 \\
(0.021)\end{array}$ & $\begin{array}{l}-0.59 \\
(0.030)\end{array}$ \\
\hline Diabetes & $\begin{array}{l}18.8 \% \\
(600805)\end{array}$ & $\begin{array}{l}5.06 \\
(0.006)\end{array}$ & $\begin{array}{l}35.04 \\
(0.028)\end{array}$ & $\begin{array}{l}37.18 \\
(0.014)\end{array}$ & $\begin{array}{l}-2.14 \\
(0.031)\end{array}$ & $\begin{array}{l}44.22 \\
(0.031)\end{array}$ & $\begin{array}{l}45.01 \\
(0.015)\end{array}$ & $\begin{array}{l}-0.79 \\
(0.034)\end{array}$ \\
\hline $\begin{array}{l}\text { Angina/coronary } \\
\text { heart disease }\end{array}$ & $\begin{array}{l}18.6 \% \\
(596323)\end{array}$ & $\begin{array}{l}5.94 \\
(0.005)\end{array}$ & $\begin{array}{l}35.49 \\
(0.032)\end{array}$ & $\begin{array}{l}37.07 \\
(0.015)\end{array}$ & $\begin{array}{l}-1.58 \\
(0.037)\end{array}$ & $\begin{array}{l}44.66 \\
(0.039)\end{array}$ & $\begin{array}{l}44.85 \\
(0.016)\end{array}$ & $\begin{array}{l}-0.25 \\
(0.041)\end{array}$ \\
\hline
\end{tabular}

\section{Relative burden of Parkinson's disease}

After adjusting for age, sex, race, education, and 15 self reported co-morbidities, the mean PCS and MCS scores of veterans with Parkinson's disease were lower than those of veterans with seven other chronic conditions by one to three points (table 4, columns 4 and 7). Subjects with spinal cord injury had a slightly lower mean PCS score than subjects with Parkinson's disease ( $32.38 v 32.72 ; 0.03$ of 1 SD). Depression patients had a markedly lower mean MCS score (35.94 v 41.48; 0.55 of $1 \mathrm{SD}$ ).

\section{Unique effects}

The adjusted PCS and MCS scores of veterans with Parkinson's disease were, respectively, 4.10 and 3.42 points ( 0.41 and 0.34 of 1 SD) lower than those of veterans who did not have Parkinson's disease (table 4, columns 6 and 9). Three other diseases had larger unique effects on PCS (arthritis, -5.44 ; chronic low back pain, -5.14 ; spinal cord injury, -4.55$)$, but subjects self reporting arthritis and low back pain had higher adjusted PCS scores than subjects with Parkinson's disease ( 34.15 and $33.76 v 32.72$ ). Only depression had a larger

Table 5 The independent effects of age, sex, race, and education on health related quality of life, controlling for Parkinson's disease and 15 self reported co-morbid conditions

\begin{tabular}{|c|c|c|c|c|c|c|c|c|c|}
\hline & & \multirow{2}{*}{$\begin{array}{l}\text { Per cent of core } \\
\text { population }\end{array}$} & \multirow[b]{2}{*}{ Weighted n* } & \multicolumn{3}{|c|}{ Physical component summary } & \multicolumn{3}{|c|}{ Mental component summary } \\
\hline \multicolumn{2}{|c|}{ Independent variable } & & & $\beta$ & SE & $\mathrm{p}$ Value & $\beta$ & SE & $\mathrm{p}$ Value \\
\hline Age & $\begin{array}{l}18 \text { to } 50 \text { years } \\
51 \text { to } 64 \text { years } \\
\geqslant 65 \text { years } \\
\text { Total }\end{array}$ & $\begin{array}{r}25.8 \% \\
29.7 \% \\
44.5 \% \\
100.0 \%\end{array}$ & $\begin{array}{r}824213 \\
950155 \\
1422415 \\
3196784\end{array}$ & $\begin{array}{l}1.821 \\
0.959 \\
0.000\end{array}$ & $\begin{array}{l}(0.041) \\
(0.031) \\
(0.000)\end{array}$ & $\begin{array}{l}\dagger \\
\dagger\end{array}$ & $\begin{array}{r}-3.244 \\
-1.755 \\
0.000\end{array}$ & $\begin{array}{l}(0.044) \\
(0.033) \\
(0.000)\end{array}$ & $\begin{array}{l}\dagger \\
\dagger\end{array}$ \\
\hline Sex & $\begin{array}{l}\text { Male } \\
\text { Female } \\
\text { Total }\end{array}$ & $\begin{array}{r}95.2 \% \\
4.8 \% \\
100.0 \%\end{array}$ & $\begin{array}{r}2914712 \\
146518 \\
3061230\end{array}$ & $\begin{array}{r}-0.048 \\
0.000\end{array}$ & $\begin{array}{l}(0.069) \\
(0.000)\end{array}$ & 0.486 & $\begin{array}{r}-0.935 \\
0.000\end{array}$ & $\begin{array}{l}(0.074) \\
(0.000)\end{array}$ & $\dagger$ \\
\hline Race & $\begin{array}{l}\text { White } \\
\text { Black } \\
\text { Other } \\
\text { Total }\end{array}$ & $\begin{array}{r}72.9 \% \\
15.4 \% \\
11.7 \% \\
100.0 \%\end{array}$ & $\begin{array}{r}2237175 \\
473000 \\
359036 \\
3069211\end{array}$ & $\begin{array}{r}0.266 \\
-0.323 \\
0.000\end{array}$ & $\begin{array}{l}(0.041) \\
(0.052) \\
(0.000)\end{array}$ & $\begin{array}{l}\dagger \\
\dagger\end{array}$ & $\begin{array}{l}1.237 \\
0.286 \\
0.000\end{array}$ & $\begin{array}{l}(0.045) \\
(0.058) \\
(0.000)\end{array}$ & $\begin{array}{l}\dagger \\
\dagger\end{array}$ \\
\hline Education & $\begin{array}{l}\leqslant 12 \text { years } \\
>12 \text { years } \\
\text { Total }\end{array}$ & $\begin{array}{r}53.8 \% \\
46.2 \% \\
100.0 \%\end{array}$ & $\begin{array}{l}1584082 \\
1362705 \\
2946787\end{array}$ & $\begin{array}{r}-1.981 \\
0.000\end{array}$ & $\begin{array}{l}(0.027) \\
(0.000)\end{array}$ & $\dagger$ & $\begin{array}{r}-2.479 \\
0.000\end{array}$ & $\begin{array}{l}(0.029) \\
(0.000)\end{array}$ & $\dagger$ \\
\hline
\end{tabular}

*Total weighted core population, 3199 209, but data are incomplete for some variables.

$\dagger p<0.001$. 
negative impact on MCS than Parkinson's disease $(-12.95 \mathrm{v}$ $-3.42 ; 1.3 v 0.34$ of $1 \mathrm{SD}$ ).

The independent effects on PCS and MCS of age, sex, race, and education are shown in table 5. Men had a lower MCS on average by 0.94 of a point than women. Younger age groups had higher mean PCS scores (by one to two points) and lower mean MCS scores (by 1.75 to 3.24 points) than subjects aged over 65 years. Having no education beyond high school reduced PCS and MCS scores by 1.98 and 2.48 points, respectively.

\section{DISCUSSION}

The analysis quantifies the extent of the negative impact of Parkinson's disease on HRQoL, as measured by the V/SF-36, controlling for the effect of four sociodemographic variables and 15 co-morbid conditions. The results confirm that people with Parkinson's disease carry a relatively heavy illness burden in both physical and mental dimensions of HRQoL compared with those suffering from eight other neurological or chronic conditions.

After removing the effect of sociodemographic factors and other diseases, the PCS and MCS scores for veterans with Parkinson's disease were lower than those for veterans with angina/coronary heart disease, arthritis, diabetes, chronic low pack pain, congestive heart failure, and stroke. Only subjects with spinal cord injury and depression recorded a lower HRQoL than those with Parkinson's disease. Individuals with spinal cord injury had mean PCS scores that were slightly below (by 0.34 points) those of the Parkinson's disease subjects, but their mean MCS scores were 2.52 points higher. On average, the MCS of subjects with depression was 5.44 points lower than that of subjects with Parkinson's disease, although their mean PCS was 3.16 points higher. The relatively low HRQoL of subjects with Parkinson's disease was not surprising, given the plethora of physical and social problems attributed to this disease. ${ }^{34}$

The unique effect of Parkinson's disease is to lower PCS by an average of 4.10 points below that of people without a diagnosis of Parkinson's disease. Although chronic low back pain and arthritis imposed larger negative effects on the physical dimensions of HRQoL than Parkinson's disease, the mean PCS scores for those conditions were higher. Many people with Parkinson's disease suffer these co-morbidities (43\% and 58\% with self reported chronic low back pain and arthritis in the VHA large national health survey, respectively).

Only depression had a larger unique effect on mental health dimensions of HRQoL than Parkinson's disease, and markedly so $(-12.95 v-3.42$; a difference equivalent to almost $1 \mathrm{SD})$. Recent international evidence confirms that depression has a major effect on the HRQoL of people with Parkinson's disease, ${ }^{2023536}$ but the debate as to whether depression in this disorder is reactive or endogenous remains unresolved. ${ }^{37}{ }^{38}$ If depression is triggered by the same biological mechanisms that cause Parkinson's disease, the logic of calculating independent effects for both Parkinson's disease and depression might be questioned. We therefore repeated our regression analyses for PCS and MCS controlling for the same four sociodemographic variables and for a diagnosis of Parkinson's disease, but replacing the 15 individual comorbidities with a count of the co-morbidities reported by survey respondents.

This revised specification does not show disease relativities, and compared with the extended models it reduces explanatory power ( $R^{2}$ of PCS, $28.1 \% \vee 33.1 \%$; MCS, $22.3 \% \vee 38.7 \%$ ). The results of the reduced model (not reported here in full) showed that the mean impact of one chronic disease was to lower HRQoL by about 0.25 of 1 SD (PCS, $\beta-2.678$, SE 0.006 , $\mathrm{p}<0.001$; MCS, $\beta-2.540$, SE 0.006, $\mathrm{p}<0.001)$. The impact of age, sex, race, and education were very similar to those in the extended version.
Removing adjustment for individual diseases had very little effect on mean PCS of veterans with Parkinson's disease or on the associated effect size coefficients $(32.93 v 32.72 ;-3.90 v$ -4.10 in the reduced and extended models, respectively). However, when depression was not explicitly controlled for, the mean MCS of subjects with Parkinson's disease fell by nearly two points (from 41.48 to 39.56 ), and the negative unique effect of Parkinson's disease became -5.37 (compared with -3.42 ). This is not surprising given that depression is a major determinant of MCS, $43 \%$ of survey respondents with Parkinson's disease self reported a previous diagnosis of depression, and the mean MCS, of subjects with depression was lower than that of subjects with Parkinson's disease by a considerable margin. It has been shown that people with Parkinson's disease adapt differently to their illness, depending on their physical status, psychological attitude, and social support. ${ }^{39}{ }^{40}$ While there is no simple relation between disability and depression, ${ }^{41}$ coping and behavioural strategies may reduce depressive symptoms. ${ }^{42}{ }^{43}$

Published reports have shown that the MOS version of the SF-36 is psychometrically sound for measuring HRQoL of people with Parkinson's disease. More advanced disease stage (measured by the unified Parkinson's disease ranking scale and the Hoehn and Yahr index), and complications such as dyskinesia, have been associated with lower SF-36 component and scale scores. Also, few floor or ceiling effects were found when SF-36 was used with people with Parkinson's disease. ${ }^{9445}$ Moreover, high correlations have been recorded between SF-36 and similar scales on the disease specific PDQ-39. ${ }^{46}$

There are several limitations to this study. First, it was a cross sectional sample and therefore the associations between variables described were purely descriptive and cannot imply causality. Second, co-morbidities and HRQoL were self reported, and correlated error may inflate the regression coefficients in some of these models and exaggerate the unique effects. However, the magnitude of the impact of comorbidities on HRQoL has been described previously and our results corroborate those findings. ${ }^{27}$ Third, there are selection effects arising because patients chose to use the VHA. We do not have internal data to model those effects, so adjustments for age or other demographics may be biased. However, the coefficients generated in the models presented are not all that different from those reported using a non-VHA population. ${ }^{17}$

The VHA population is different in many respects from the general populations, including the predominance of service related occupations and of male enrollees. The VHA population (mean PCS, 36.91; MCS, 45.08) carries a greater disease burden than the US civilian population (mean PCS, 43.60; MCS, 52.30) by more than one half of 1 SD. ${ }^{19}$ Moreover, the distribution of illness is different in VHA in that younger groups in VHA have worse SF-36 scores in all but the physical functioning scale. ${ }^{27}$ A community based study that used SF-36 to investigate the HRQoL of 228 people with Parkinson's disease in Finland found that women scored significantly lower than men in five of the scales, and confirmed the central role of depression in impairing HRQoL. ${ }^{46}$

Some observers have noted that people with chronic diseases rate their HRQoL higher than their physicians. ${ }^{47}$ In this regard, the concept of response shift has received attention. ${ }^{48}$ Like the disability paradox,${ }^{49}$ it refers to the possibility that people with chronic illnesses adjust their internal standards and values to accommodate the realities of their condition. It is suggested that they recalibrate their assessment of disability ${ }^{50}$ and, as a result of lowered expectations, ${ }^{51}$ they self report a higher quality of life than a healthy person would assign to any given level of impaired functioning. Existing measures of HRQoL do not show response shift because they do not relate self reported experiences to expectation. ${ }^{52}$ To the extent that it occurs, response shift depresses disease effect sizes which are calculated as the 
difference between a clinical group and the general population. It is unimportant in intercondition comparisons, however, unless it has differential impact across diseases.

\section{Conclusions}

Despite differences between the VHA and non-VHA populations, the proportion of people with Parkinson's disease in the VHA (1.6\%) is equivalent to broader population estimates. ${ }^{53}$ Other American evidence, based on a sample of 193 individuals with Parkinson's disease completing SF-36 in an outpatient setting, confirms that most subjects had lower scores than the general public on most dimensions, but showed that PCS, and to a lesser extent MCS, varied with disease severity. ${ }^{95} 54$ The scores calculated in the present study are averages, and closer inspection of available data is required to see how generic self reported HRQoL in the VHA population varies with clinical indicators and service utilisation. The findings so far suggest, however, that the relative illness burden of veterans in the VHA with Parkinson's disease is high in both physical and mental dimensions of HRQoL, and thereby reinforce the case for multiprofessional team approaches to management. ${ }^{556}$

\section{ACKNOWLEDGEMENTS}

This research was supported in part by the Center for Health Quality, Outcomes and Economic Research (CHQOER), VAMC, Bedford, Massachusetts, USA, the Department of Veterans Affairs, Health Services Research and Development Service and the Office of Quality and Performance (10Q), Washington DC, USA. The views expressed in this article are those of the authors and do not necessary represent the views of the Department of Veterans Affairs, Health Services Research and Development or the Office of Quality and Performance. We especially thank Yumiko Stenstrum for her assistance.

\section{Authors' affiliations}

H Gage, Department of Economics, University of Surrey, Guildford, Surrey, UK

A Hendricks, S Zhang, L Kazis, Center for Health Quality, Outcomes and Economic Research (CHQOER), Bedford, Massachusetts, USA

Competing interests: none declared

\section{REFERENCES}

1 Abudi S, Bar-Tar Y. Parkinson's disease symptoms - patients' perceptions. J Adv Nurs 1997:25:54-9.

2 Devinsky O. Outcome research in neurology: incorporating health-related quality of life. Ann Neurol 1995;37:141-2.

3 Scheife R, Schumack G, Burstein A, et al. Impact of Parkinson's disease and its pharmacologic treatment on quality of life and economic outcomes. Am J Health Syst Pharm 2000;57:953-62.

4 Addington-Hall J, Kalra L. Who should measure quality of life? BM 2001;322:1417-20

5 Deyo R. The quality of life, research and care. Ann Intern Med 1991;114:695-6.

6 Nijof G. Parkinson's disease as a problem of shame in public appearance. Sociol Health Illness 1995; 17:193-205.

7 Pentland B, Barnes M, Findley L, et al. Parkinson's disease - the spectrum of disabilities. J Neurol Neurosurg Psychiatry 1992;55(suppl):32-5.

8 Meyers AR, Gage H, Hendricks A. Health-related quality of life in neurology. Arch Neurol 2000;57:1224-7.

9 Christalles E, Rubenstein L, Voelker $M$, et al. The health burdens of Parkinson's disease. Mov Disord 1998:13:406-13.

10 Editorial. Quality of life and clinical trials. Lancet 1995;346:1-2.

11 Idler E, Benyamini Y. Self-rated health and mortality: a review of twenty-seven community studies. J Health Soc Behav 1997;38:21-37.

12 Carr AJ, Higginson J. Are quality of life measures patient centered? BM 2001:322:1357-60.

13 Kaplan RM. Profile versus utility based measures of outcome for clinical trials. In: Staquet N, Hays RD, Fayers PM, eds. Quality of life assessment in clinical trials. Oxford: Oxford University Press, 1998:69-90.

14 Koch T. Life quality versus the "quality of life": assumptions underlying prospective quality of life instruments in health care planning. Soc $\mathrm{Sci}$ Med 2000;51:419-27.

15 Kizer KW. Re-engineering the Veterans Health Care System. In: Ramsaroop P, Ball M, Beaulieuu D, et al, eds. Advancing federal sector health care. New York: Springer Verlag, 2000:79-96.

16 Kazis LE. The Veterans SF-36 health status questionnaire: developmen and application in the Veterans Health Administration. Medical Outcomes Trust Monitor 2000;5(1)
17 Ware JE, Bayliss MS, Rogers WH, et al. Differences in 4-year health outcomes for elderly and poor, chronically ill patients treated in $\mathrm{HMO}$ and fee-for-service systems. JAMA 1996;276:1039-47.

18 Kazis LE, Ren XS, Skinner K, et al. Health status in VA patients: results from the veteran's health study using the Veterans SF-36. Am J Med Qual 1999; 14:28-38.

19 Kazis L, Skinner KM, Ren XS, et al. Health status and outcomes of veterans: physical and mental component summary scores. Veterans SF-36; 1999 large health survey of veteran enrollees. Executive report. Washington, DC: Department of Veterans Affairs, Veterans Health Administration, Office of Quality and Performance, 2000.

20 Schrag A, Jahanshahi M, Quinn N. What contributes to quality of life in patients with Parkinson's disease? J Neurol Neurosurg Psychiatry 2000;69:308-12

21 Fukunaga $\mathbf{H}$, Kasai T, Yoshidome $\mathrm{H}$. Clinical findings, status of care, comprehensive quality of life, daily life therapy and treatment at home in patients with Parkinson's disease. Eur Neurol 1997;38(suppl 2):64-9.

22 Karlsen KH, Larsen J, Tandberg E, et al. Influence of clinical and demographic variables on quality of life in patients with Parkinson's disease. J Neurol Neurosurg Psychiatry 1999;66:431-5.

23 McDowell I, Newell C. Measuring health: a guide to rating scales and questionnaires. Oxford: Oxford University Press, 1996:446-56.

24 Shen Y, Hendricks A, Kazis L. Health insurance and use of services by veterans; 1999 large health survey of veteran enrollees. Executive report. Washington, DC: Department of Veterans Affairs, Veterans Health Administration, Office of Quality and Performance, 2000.

25 Ware JE. SF-36 health survey manual and interpretation guide. Boston: The Health Institute, 1993

26 Ware JE, Kosinski M, Keller SD. SF-36 physical and mental health summary scales: a users manual. Boston: Health Assessment Laboratory, New England Medical Center, 1994.

27 Kazis LE, Skinner K, Rogers W, et al. Health status and outcomes of veterans: physical and mental component summary scores (SF-36V). 1998 National survey of ambulatory care patients, mid-year executive report. Washington, DC: Department of Veterans Affairs, Veterans Health Administration, Office of Quality and Performance, 1998.

28 Kazis LE, Miller DR, Clark J, et al. Health related quality of life in patients served by the Department of Veterans Affairs: results from the Veterans Health Study. Arch Intern Med 1998;158:626-32

29 Ware JE, Sherbourne CD. The MOS 36-item short-form health survey (SF-36). I. Conceptual framework and item selection. Med Care 1992;30:473-83

30 McHorney CA, Ware JE, Raczek AE. The MOS 36-item short-form health survey (SF-36). II. Psychometric and clinical tests of validity in measuring physical and mental health constructs. Med Care 1993:31:247-63.

31 McHorney CA, Ware JE, Lu JFR. The MOS 36-item short-form health survey (SF-36). III. Tests of data quality scaling assumptions and reliability across diverse patient groups. Med Care 1994;32:40-66.

32 Ware JE, Kosinski M, Bayliss MS. Comparison of methods for the scoring and statistical analysis of SF-36 health profile and summary measures; summary of results from Medical Outcomes Study. Med Care 1995;33:AS264-79.

33 Shah BV, Barnwell BG, Bieler GS. SUDAAN user's manual, release 7.5 Research Triangle Park, NC: Research Triangle Institute, 1997.

34 Martinez-Martin P. An introduction to the concept of "quality of life" in Parkinson's disease. J Neurol 1998;245(suppl):S2-6.

35 Phillips P. Keeping depression at bay helps patients with Parkinson's disease. JAMA 1999;202:1118-19.

36 Rektrova I. The global Parkinson's disease survey - update. European Parkinson's Disease Magazine 2001;18:14-15.

37 Dakof G, Mendelsohn G. Parkinson's disease: the psychological aspects of a chronic illness. Psychol Bull 1986;99:375-87.

38 Brown R, Jahanshaki M. Depression in Parkinson's disease: a psychosocial view point. In: Weiner W, Lang A, eds. Adv Neurol 1995;65: chapter 5.

39 Dakof G, Mendelsohn G. Patterns of adaptation to Parkinson's disease. Health Psychol 1989;8:355-72.

40 Gotham AM, Brown RG, Marsden FD. Depression in Parkinson's disease: a quantitative and qualitative analysis. J Neurol Neurosurg Psychiatry 1986:49:381-9.

41 MacCarthy B, Brown R. Psychosocial factors in Parkinson's disease. Br J Clin Psychol 1989;28:41-52.

42 Ehman J, Beninger R, Gawel M, et al. Coping, social support, and depressive symptoms in Parkinson's disease. J Geriatr Psychiatry Neurol 1990:3:85-90.

43 Ellgring $\mathbf{H}$, Seiler S, Perleth B, et al. Psychosocial aspects of Parkinson's disease. Neurology 1993;43(suppl 6):S41-4.

44 Damieno AM, McGrath MM, Willian MK, et al. Evaluation of a measurement strategy for Parkinson's disease: assessing patient health-related quality of life. Qual Life Res 2000;9:87-100.

45 Rubinstein LM, Voelker MD, Christalles EA, et al. The usefulness of the functional status questionnaire and medical outcomes study short-form in Parkinson's disease research. Qual Life Res 1998;7:279-90.

46 Kuopio AM, Marttila RJ, Helenius $\mathrm{H}$, et al. The quality of life in Parkinson's disease. Mov Disord 2000;15:216-23.

47 Pearlman RA, Uhlman RF. Quality of life in chronic disease: perceptions of elderly patients. J Gerontol 1988;43:M25-30

48 Sprangers $M$, Schwartz $C$. Integrating response shift into health-related quality of life research: a theoretical model. Soc Sci Med 1999:48:1507-15.

49 Albrecht GL, Devlieger PJ. The disability paradox: high quality of life against the odds. Soc Sci Med 1999;48:977-88. 
50 Daltroy L, Larson $M$, Eaton $\mathrm{H}$, et al. Discrepancies between self-reported and observed physical function in the elderly: the influence of response shift and other factors. Soc Sci Med 1999;48:1549-61

51 Nordeson A, Engström B, Norberg A. Self-reported quality of life for patients with progressive neurological diseases. Qual Life Res 1998;7:257-66

52 Carr AJ, Gibson B, Robinson G. Is quality of life determined by expectations or experience? BM 2001;322:1240-43

53 Schapira A. Parkinson's disease. BM 1999;318:311-14.
54 Rubinstein LM, DeLeo A, Christalles EA. Economic and health-related quality of life considerations of new therapies in Parkinson's disease. Pharmacoeconomics 2001;19:729-52.

55 Lieberman A. An integrated approach to patient management in Parkinson's disease. Neurol Clin 1992;10:553-65.

56 Cutson T, Cotter Laub K, Schenkman M. Pharmacological and non-pharmacological interventions in the treatment of Parkinson's disease. Phys Ther 1995;75:363-3.

\section{HISTORICAL NOTE}

\section{Pick's disease}

A nold Pick (1851-1924) ${ }^{1}$ was born of German-Jewish parents on 20 July 1851 in Velké Mezirici, in Moravia. ${ }^{2}$ He studied medicine in Vienna, where Theodore Meynert (1833-1892) stimulated his neurological interests. As with many medical scholars of his time, he was trained in clinical neurology, psychiatry, and neuropathology, a wide spectrum of disciplines now seldom feasible. In 1874 he trained in Berlin with Westphal, and from 1875 he worked at the later infamous asylum of Wehnen. Then he became lecturer in neurology and psychiatry in Prague where he met Otto Kahler, with whom he published papers on oculomotor palsies, cortical localisation, and syringomyelia. They established 'Kahler-Pick's law' -incoming fibres in the posterior columns of the cord from a higher level displace medially those that enter at a lower level.

He found promotion to the chair of neuropsychiatry in Prague but encountered many problems related to academic teaching in both German and Czech languages, controlled by the Austro-Hungarian empire. Essential provisions were often lacking and he met with much hostility and resentment ${ }^{1}$ that often hampered his work. Despite this, his remarkable ability to communicate with patients with psychoses and aphasia was admired, and his history-taking became legendary.

An intellectual man, Pick loved classical music and in his home his books in many languages were piled from floor to ceiling. He was described as a "noble minded, excessively modest but fearless man, the essence of calm serenity". ${ }^{2}$ He retired in 1921, but continued some work, despite troublesome cataracts and urinary tract stones. On 4 April 1924, at the age of 73, he died of urinary sepsis following bladder surgery.

Pick published about 350 papers on diverse topics. Many were case reports dealing with neuropsychology and behavioural neurology. He was among the first to give reliable descriptions of visual hallucinations, micrographia, palilalia, and reduplicating paramnesia. He wrote important papers on apraxia and aphasia. ${ }^{3}$ He described the fibre bundles in the medulla oblongata (Pick's bundle). His 1898 book on neuropathology was a landmark in this field.

In his work on aphasia he introduced the term agrammatism. Agrammatical speech was the basic defect of aphasic disorders. Wernicke influenced his views on language but Jackson probably had a greater influence on his concepts of how language was disrupted. They had great mutual respect and shared a distaste for speculation; both wrote in terse prose.

\section{Pick's disease}

In 1892, Pick described a 71 year old man who presented with progressive loss of language and a failing mind. ${ }^{5}$ After death, the brain showed asymmetrical atrophy as opposed to the more diffuse atrophy of Alzheimer's disease. The condition described by Pick "on the relationship between senile atrophy of the brain and aphasia" ${ }^{\prime 6}$ was often confused with Alzheimer's and vascular dementias. Pick published three further papers, in which he showed patients with severe aphasia and apraxia who had a "progressive circumscribed atrophy" of the cortex. ${ }^{7-9}$ He regarded these patients as suffering from a variant of senile dementia. Attention was drawn to the aphasic and later the apraxic side of the syndrome, but eventually the distinctive pathology established it as an entity.

Alzheimer in 1911 confirmed the circumscribed cortical (lobar) atrophy, ${ }^{10}$ and found the characteristic Pick bodies: ovoid, homogeneous, smooth-edged, and intensely argyrophilic neuronal inclusions. Gans introduced the name Pick's disease in $1922 .{ }^{11}$

J M S Pearce 304 Beverley Road, Anlaby, Hull HU10 7BG; imspearce@freenet.co.uk

\section{References}

1 Sittig O. Professor Arnold Pick H. Arch f Psychiat 1924;72: 1-20.

2 Brown MR. Arnold Pick. In: Haymaker W, Schiller F, eds. The founders of neurology. 2nd edn. Springfield: Thomas, 1970:358-62.

3 Arts NJM. Pick's disease. In: Koehler P, Bruyn G, Pearce JMS, eds. Neurological eponyms. New York: Oxford University Press, 2000:342-9.

4 Pick A. Beiträge zur pathologie und pathologischen anatomie des centralnervensystems. Mit bemerkungen zur normalen. Berlin: Karger, 1898.

5 Kertesz A. Arnold Pick: a historical introduction. In: Kertesz A, Munoz DG, eds. Pick's disease and Pick complex. New York: Wiley-Liss, 1998.

6 Pick A. Über die beziehungen der senilen hirnatrophie zur aphasie. Prager Medicinische Wochenschrift 1892;17:165-7.

7 Pick A. Senile hirnatrophie als grundlage von Herderscheinungen. Wien klin Wschr 1901;14:403-4.

8 Pick A. Zur symptomatologie der linksseitigen schläfenlappenatrophie. Monatschr Psychiat Neurol 1904;16:378-88. (Trans Hist Psychiat 1997;8:149-59.1

9 Pick A. Über einen weiterer symptomenkomplex im rahmen der dementia senilis, bedingt durch umschriebene starkere hirnatrophie. Monatschr Psychiat Neurol 1906;19:97-108.

10 Alzheimer A. Über eigenartige krankheitsfälle des späteren alters. Ztschr ges Neurol Psychiat 1911;4:356-85.

11 Gans A. Betrachtungen über art und ausbreitung des krankhaften prozesses in einem fall von Pickscher atrophie des stirnhirns. Ztschr ges Neurol Psychiat 1922;80:10-28. 